УДК 004.588:37.018.43(477.82)

DOI: 10.37026/2520-6427-2020-104-4-25-29

\section{Лариса КОНСТАНКЕВИЧ,}

викладач, викладач-методист

кафедри природничо-математичних дисииплін

Луцького педагогічного коледжу

\section{Лілія БОРЕМЧУК,}

викладач, викладач-методист

кафедри психолого-педагогічних дисииплін

Луцьького педагогічного коледжу

Мар'яна РАДКЕВИЧ,

викладач кафедри

природничо-математичних дисичплін

Луцьккого педагогічного коледжу

\title{
ВИКОРИСТАННЯ СЕРВІСУ GOOGLE CLASSROOM У ПРОЦЕСІ ДИСТАНЦЙННОГО НАВЧАННЯ
}

Стаття присвячена аналізу використання сервicy Google Classroom у проиесі дистаниійного навчання, зокрема здійснено огляд наукової літератури щьодо дистанційного навчання студентів коледжу та використання комп'ютерно оріснтованих систем навчання, досліджено особливості використання хмарного сервісу Google Classroom nid час дистанційного навчання.

Ключові слова: інформаційно-комунікаційні технології, комп ютерно орієнтовані системи, дистанціийне навчання, хмарні технології, Google Classroom, ичиррові технології, інформаційне освітнє середовище.

The article is devoted to the analysis of the use of the Google Classroom service in the process of distance learning. The present time dictates the need of organizing of distance learning to provide higher education students with the main amount of educational material, active interaction of students and teachers in the learning process, providing opportunities for independent work on learning material, assessment of knowledge and professional skills. Therefore, the problem of finding and selecting the most accessible and easy to use information and communication technologies for distance learning becomes more actual. The usage of which will ensure the creation, transfer and storage of educational materials, active communication and support of the educational process in higher education. Consequently the article considers the concept of distance learning, analyzes the scientific literature on distance learning of students of the college and the use of computer-based learning systems. The peculiarities of using the Google Classroom cloud service in the learning process during distance learning are considered, as well. The general information about the Google classroom cloud service and its services is provided. The use of Google services in the educational process not only contributes to the main aim of modern education - the formation of a competitive and successful personality in the electronic information society, but also significantly improves and diversifies the teacher, activates students' creativity, creates appropriate conditions for their formation, development and skills, improves the assimilation and reproduction of information obtained by them.

Key words: information and communication technologies, computer-saved systems, distance learning, special training programs, Google Classroom, digital technologies, information information environments.

Постановка проблеми. У сучасному світі проблемі якості освіти приділяється чимало уваги, зокрема активно розробляються нові форми та методи організації управління освітніми процесами, нові освітні методики, здатні замінити традиційні форми представлення інформації з метою підвищення якості навчання. Однією із таких методик є технологія дистанційного навчання, яка останнім часом стрімко розвивається та запроваджується у провідних навчальних закладах світу [5, с. 173-180].

Сьогодення диктує необхідність організації дистанційного навчання $з$ метою забезпечення здобувачів вищої освіти основним обсягом навчального матеріалу, активної взаємодії студентів та викладачів у процесі навчання, надання можливості для самостійної роботи із засвоєння навчального матеріалу, оцінювання отриманих знань і професійних умінь. У зв'язку з цим неабиякої актуальності набуває проблема пошуку та вибору доступних і простих у використанні інформаційно-комунікаційних технологій дистанційного навчання, що забезпечило б створення, передавання та зберігання навчальних матеріалів, активну комунікацію і супровід навчального процесу в закладах вищої освіти.

На сьогодні одним із найпопулярніших сервісів для навчання студентів є Google Classroom (https://classroom.google.com), використання якого дозволяє організувати ефективну взаємодію всіх учасників освітнього процесу, розподілити навчальний матеріал і забезпечити необхідним програмним забез-печенням з метою виконання різних навчальних завдань, оцінювання навчальних досягнень здобувачів освіти. 
Аналіз наукових досліджень і публікацій. Ідея використання хмарних технологій у процесі дистанційного навчання все частіше аналізується у науковій та педагогічній літературі, зокрема іiі досліджували такі українські дослідники, як Н. В. Морзе, Н. В. Кузьмінська, С. О. Семеріков, В. П. Сергієнко, І. С. Войтович, В. Ю. Биков, Г. Ю. Маклаков, Н. В. Сороко, Т. А. Вакалюк, Ю. Г. Лотюк [3]. У своїх роботах науковці розглядають питання, що стосуються загальної теорії використання хмарних технологій в освіті, створення тестів та організації тестування на базі хмарних середовищ, упровадження хмарних класів для дистанційного навчання тощо.

Зважаючи на велику кількість наукових досліджень в означеному напрямку, хмарні технології знаходяться в постійному розвитку, створюються нові online-сервіси та середовища, які потребують детального вивчення 3 метою їх використання в навчальному процесі [6].

Мета статті - проаналізувати основні можливості сервісу Google Classroom у процесі організації дистанційного навчання.

Виклад основного матеріалу. Корпорація Google розробляє й надає в користування велику кількість додатків і сервісів, доступ до яких можливий у вікні будь-якого браузера (Mozilla Firefox, Google Chrome, Opera, Internet Explorer та ін.) за умови підключення до мережі Інтернет. Важливу роль 3-поміж означених додатків і сервісів відіграють Google Apps for education (додатки Google для освіти) - безкоштовні вебсервіси для навчальних закладів, що надаються компанією Google [2, с. 215-218].

У 2014 році компанія Google запустила сервіс Google Classroom (Google Клас) [1], який надає зручний інтерфейс для створення й керування навчальними курсами. Запропонована освітня платформа характеризується простотою у використанні, а також надає користувачам зручний інтерфейс для керування навчальним процесом.

Перевагами використання Google Classroom є:

- просте налаштування (викладач має можливість організувати декілька курсів одночасно, планувати навчальний процес, запрошувати до роботи студентів та викладачів);

- зручність у використанні (студенти можуть переглядати завдання, планувати строки їх виконання, вчасно надсилати виконані роботи для перевірки);

- економія часу та паперу (можливість завдяки сервісу контролювати виконання та перевіряти завдання);

- доступність і безпека.

Створюючи курс на платформі Google Classroom, викладачу необхідно увійти 3 особистого акаунту Google до відповідного додатка головного меню в браузері (див. рис. 1).

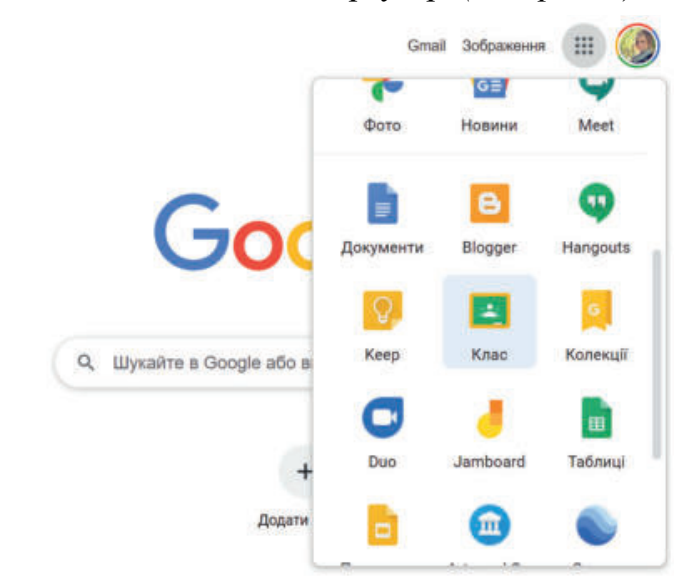

Pис. 1. Головна сторінка сервісу Google

Після обрання статусу викладача можна розпочати створення та налаштування власного класу (дuв рис. 2).

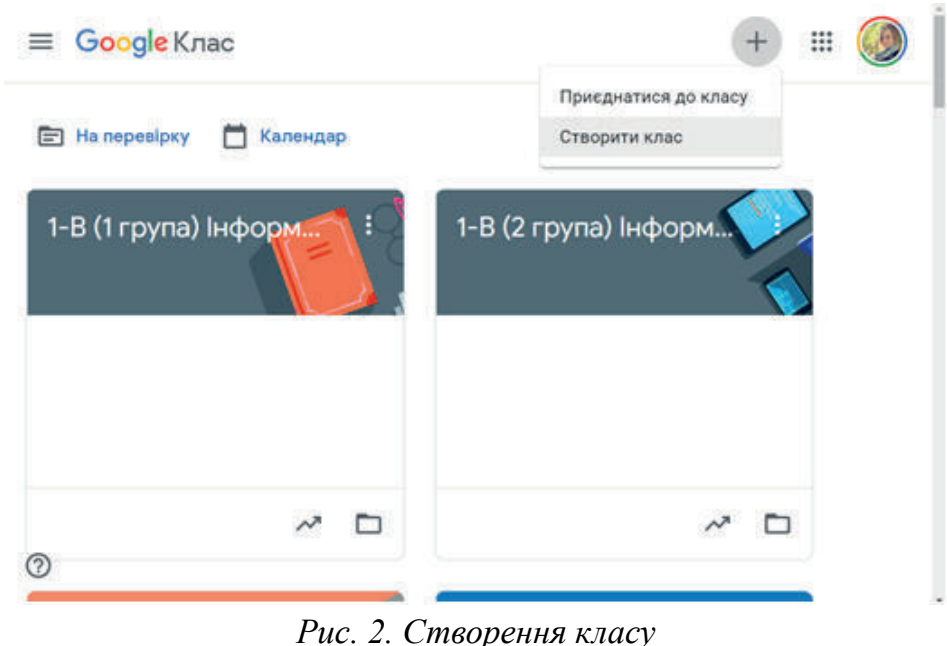

Рис. 2. Створення класу

Після створення класу викладач за допомогою меню може структурувати завдання за розділами та темами. До кожного завдання або теми можна додати термін виконання та вивчення матеріалу (див. рис. 3). 


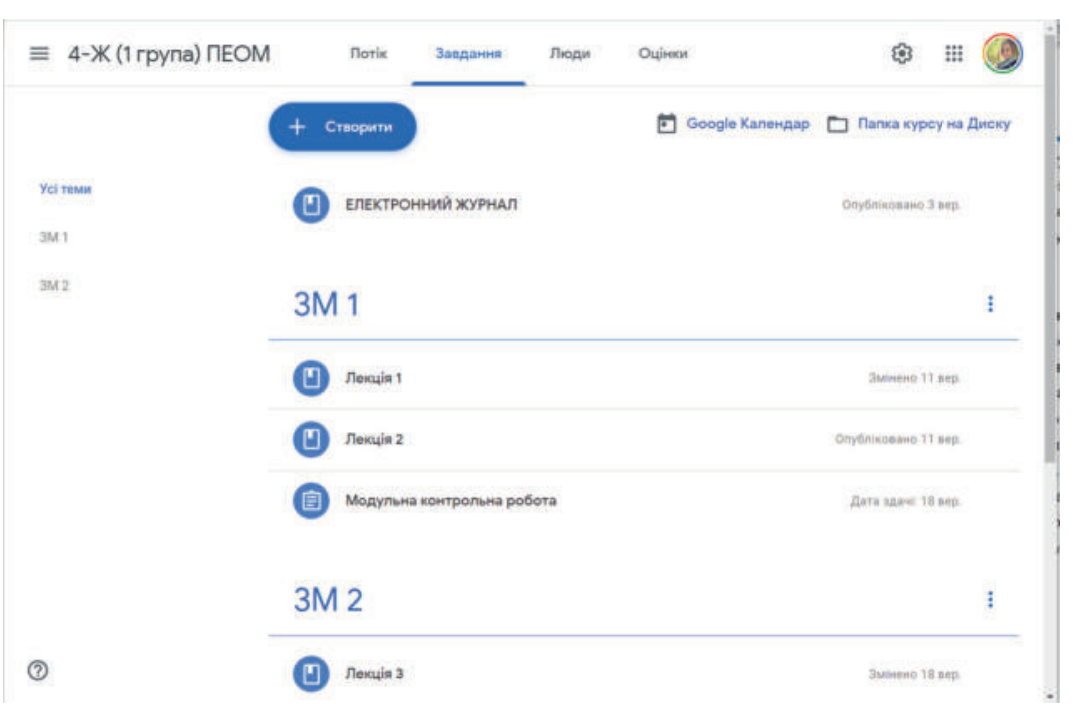

Рис. 3. Приклад оформлення класу

Важлива перевага Google Classroom - це інтегрованість з іншими сервісами Google, завдяки чому викладач має можливість завантажувати в клас інформацію у будь-якому форматі. Щоб створити завдання, потрібно обрати відповідний пункт меню. Далі в діалоговому вікні вказати тематику завдання, дати пояснення щодо оформлення та строків виконання, прикріпити саме завдання. Існує можливість створювати індивідуальні завдання для кожного студента, а також встановлювати шкалу оцінювання. Публікацію будь-якого матеріалу в Google Classroom можна запланувати. Кожна публікація (оголошення, матеріал, завдання) з'являється на сторінці «Потік», а студенти отримують сповіщення на свою електронну адресу (див. рис. 4).

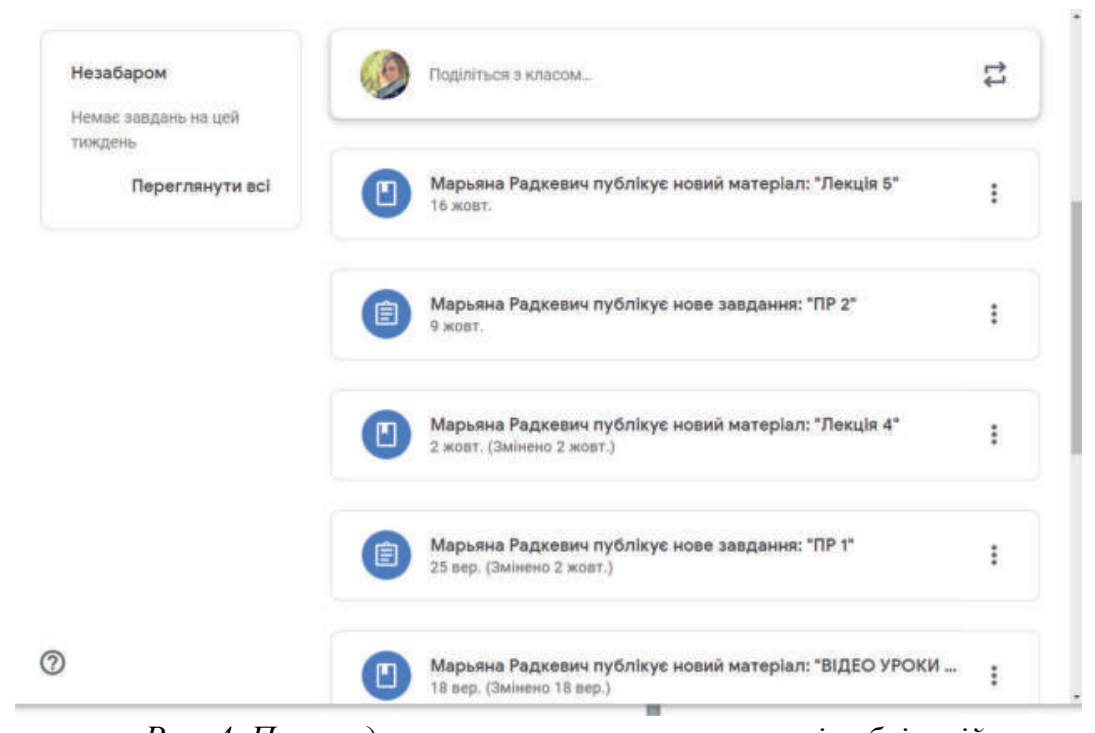

Рис. 4. Приклад створених та наявних у класі публікаціий

Google Classroom підтримує різні класифікації завдань. Викладачі мають можливість прикріплювати файли до завдання, яке студенти переглядають, редагують або копіюють. Студенти відповідно створюють файли, а потім приєднують ïх до завдання. Крім того, у кожного студента $\epsilon$ можливість стежити за ходом виконання завдання. Виконані завдання можуть бути оцінені викладачем і повернуті з коментарями, що дозволяє студенту переглянути роботу i виправити помилки (див. рис. 5).

Ще однією корисною особливістю класу є можливість архівувати курси в кінці семестру або року. Коли курс архівується, він видаляється з домашньої сторінки і переміщається в розділ «Архівні класи», щоб допомогти педагогам організувати свої поточні класи. Коли курс архівується, викладачі та студенти можуть його переглядати, проте не можуть вносити в нього жодних змін до тих пір, поки його не буде відновлено.

Минулого року в Google Classroom 3'явилася нова сторінка «Оцінки», яка доступна лише викладачам. Завдяки цій сторінці можна вивчати i змінювати дані журналу успішності, а також перевіряти, оцінювати і повертати роботи студентам (див рис. 6).

Доступ до класу можна отримати не лише 3 комп'ютера. Існують мобільні додатки Google Classroom, представлені в січні 2015 року, що доступні для пристроїв IOS та Android.

Пропонуємо переглянути створені та розроблені нами класи на платформі Google Classroom. 
$\equiv 4-Ж$ (1 група) ПЕОМ

:\#) (9)

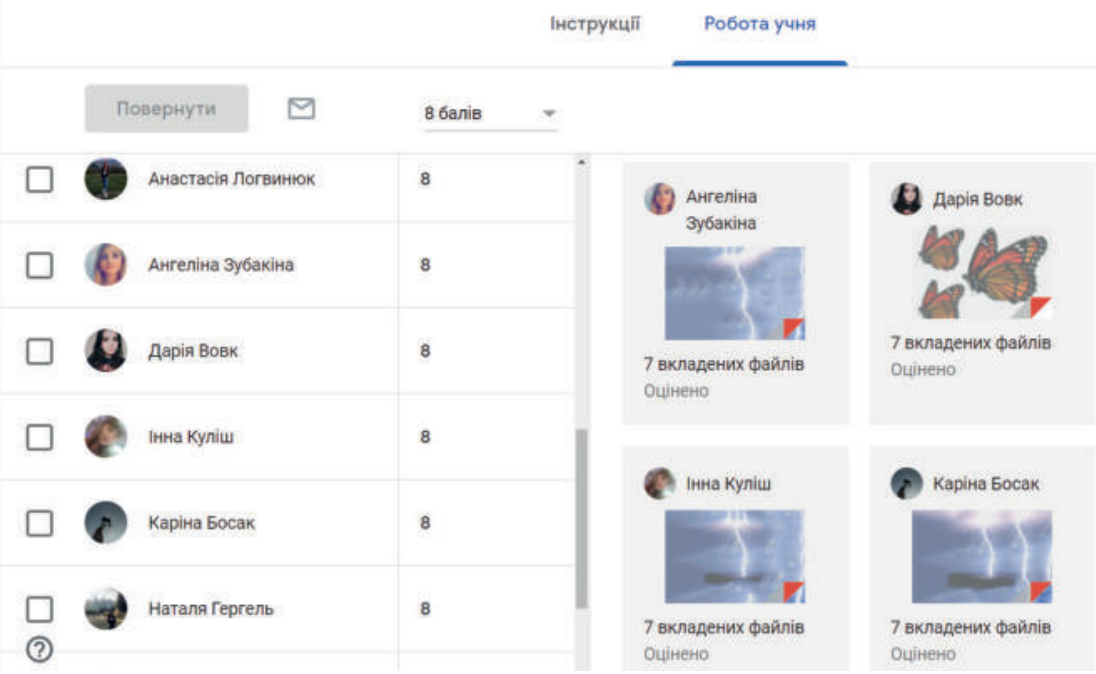

Рис. 5. Приклад оичінювання завдання у Google Classroom

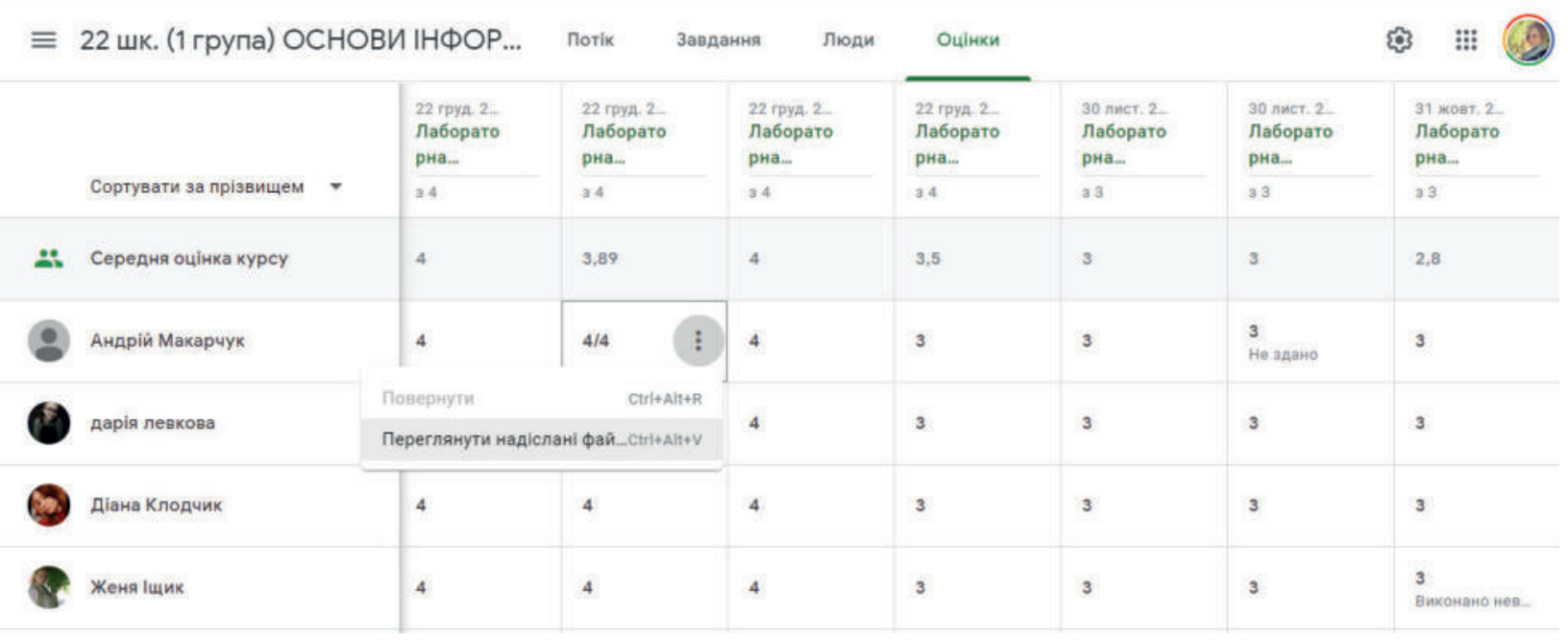

Рис. 6. Приклад сторінки «Оичінки»

$\equiv$ GoogleKrac

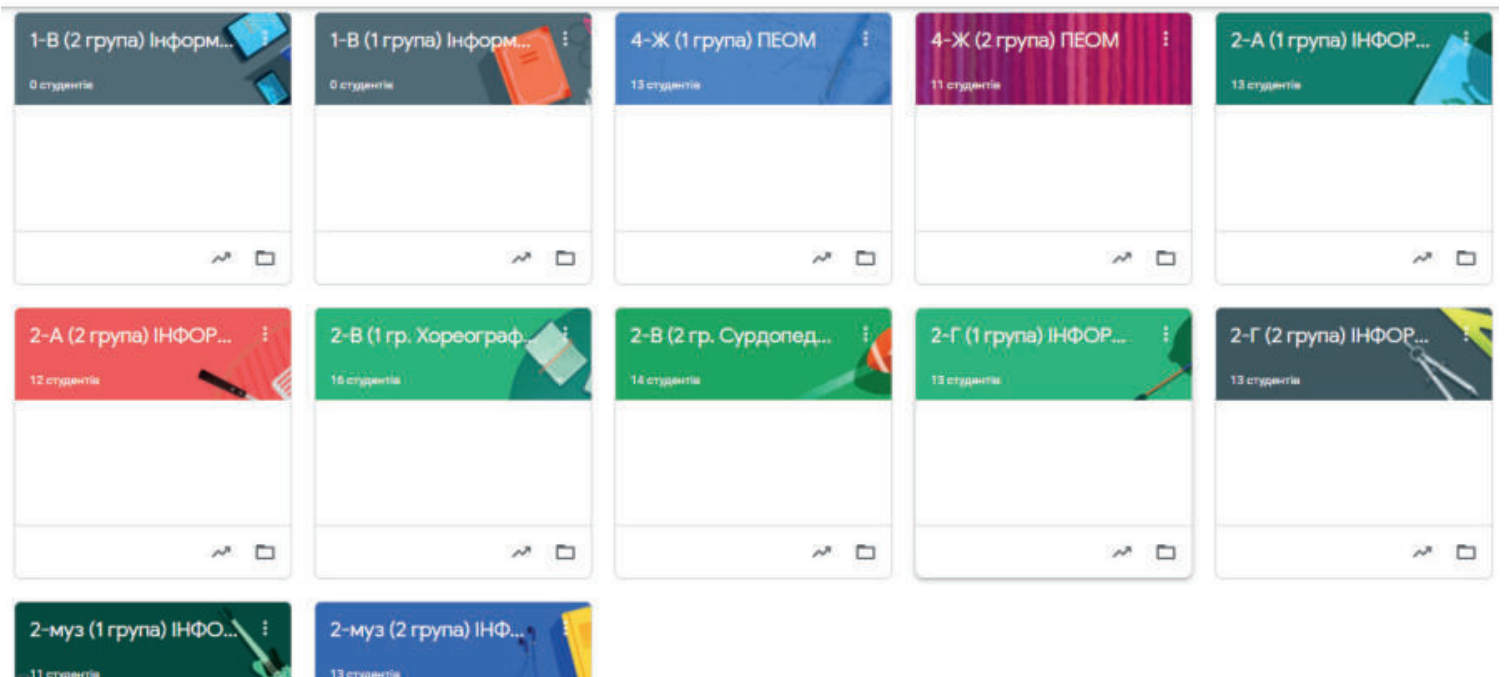

Pис. 7. Класи на платформі Google Classroom, створені та розроблені викладачем інформатики М. М. Радкевич 


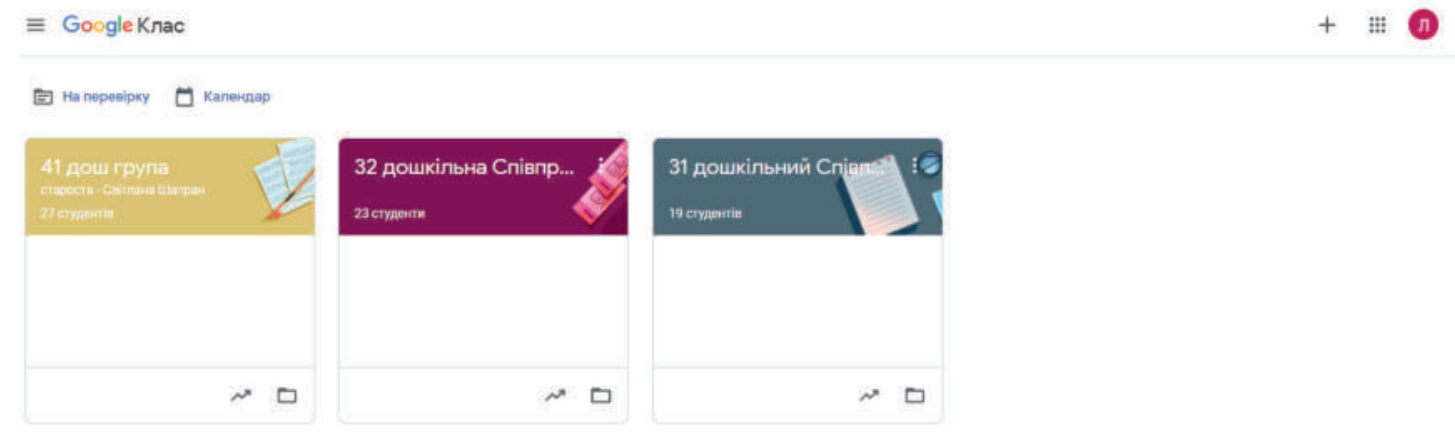

Pис. 8. Класи на платформі Google Classroom, створені та розроблені викладачем дошкільної педагогіки Л. І. Боремчук

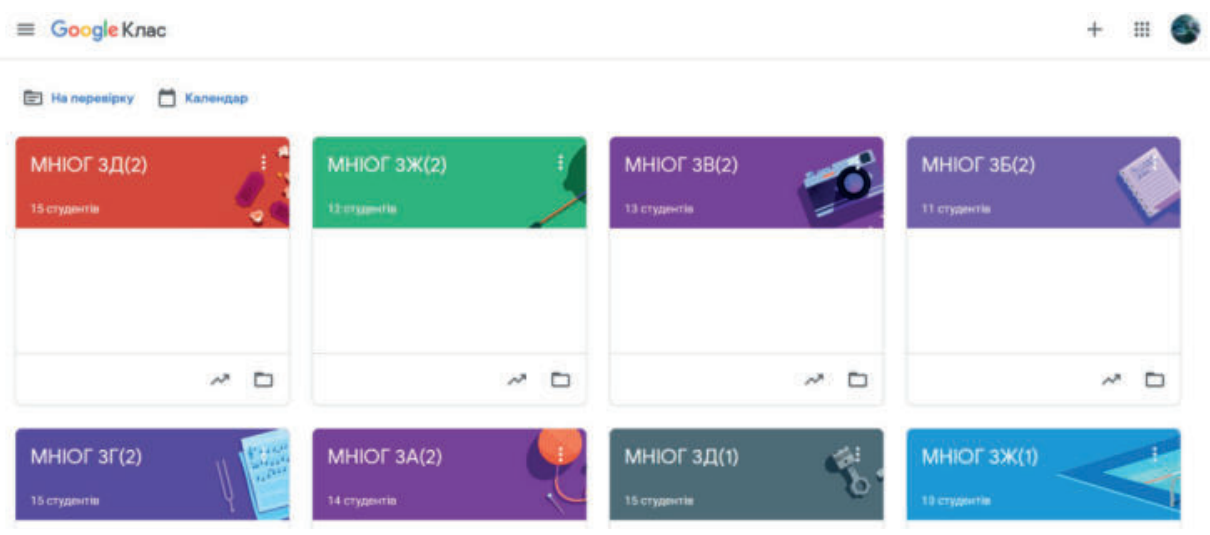

Puc. 9. Класи на платформі Google Classroom, створені та розроблені викладачем інформатики Л. Г. Констанкевич

Таким чином, використання хмарного сервісу Google Classroom у навчальному процесі в ході дистанційного навчання дозволяє індивідуалізувати навчальний процес, сприяє підвищенню мотивації до навчання, дає змогу викладачам вдало організувати навчальне середовище і активно використовувати в роботі групові форми роботи. Навчальні матеріали, розміщені на хмарному середовищі, студенти мають можливість переглядати у будь-який час як для повторення пройденого, так і для вивчення нового матеріалу.

Висновки. Отже, Google Classroom створює peальні можливості для підвищення професійної підготовки молоді, організації та урізноманітнення стандартного навчального процесу через мережу Інтернет, сприяє ефективному використанню особистого часу як викладача, так і студента. Використання сервісів Google в навчальному процесі не тільки сприяє виконанню основного завдання сучасної освіти - формуванню конкурентоспроможної й успішної особистості в електронному інформаційному суспільстві, а й значно вдосконалює й урізноманітнює діяльність викладача, активізує творчу діяльність студентів, створює належні умови для формування й розвитку у них відповідних умінь та навичок, покращує засвоєння i відтворення ними отриманої інформації.

Перспективи подальших досліджень вбачаємо у детальному вивченні змін та оновлень до сервісу Google Classroom 3 метою його застосування у процесі дистанційного навчання та самоосвіті.

\section{СПИСОК ВИКОРИСТАНОЇ ЛІТЕРАТУРИ}

1. Google Класс. Справка-Класс : вебсайт. 2015. URL: https://support.google.com/edu/classroom/answer/
$6020279 ? \mathrm{hl}=$ ru\&ref_topic $=602027$ (дата звернення: 10.07.2020).

2. Вакалюк Т. А. Основні можливості використання Google Classroom у навчально-виховному процесі ВНЗ. Комп'ютерні технологї: інновачї̈, проблеми, рішення - 2017 : матеріали II Міжнародної науково-технічної конференції. Житомир : ЖДТУ, 2017. C. $215-218$.

3. Пліш I. В. Використання інформаційно-комунікаційних технологій управління якістю освіти в школах приватної форми власності. 2012. №1 (27). URL: http://journal.iitta.gov.ua (дата звернення: 05.07.2020).

4. Побіженко I. О. Перспективи використання хмарних технологій для організації навчального процесу у вищих навчальних закладах. Харків, 2017. URL: http://www.hups.mil.gov.ua/periodic-app/article/4136/ zhups_2014_4_42.pdf (дата звернення: 10.07.2020).

5. Тарасова С. М. Інформаційно-комунікативні технології в управлінні загальноосвітнім навчальним закладом. Науковий вісник МДУ імені В. О. Сухомлинського. 2010. Вип. 1.31. С.173-180.

6. Ткачук Г. В. Хмарні технології: аналіз, перспективи, реалізації. Комп ютер у школі та сім'ї. 2015. № 2. C. 40-43. URL: http://nbuv.gov.ua/UJRN/ komp_2015_2_12 (дата звернення: 05.07.2020).

7. Чумак $\bar{Л}$. А. Можливості сервісу Google Classroom для організації навчального процесу. Вісник Придніпровської державної академії будівництва та архітектури. 2018. № 6. С. 65-70.

8. Як навчатися дистанційно? URL: http://dist. karazin.ua/for-teachers/how-teach-remotely (дата звернення: 10.07.2020).

Дата надходження до редакиї: 25.08.2020 p. 